\title{
A FORMAÇÃO EM SERVIÇO DO PROFESSOR E AS MUDANÇAS NO ENSINO DE LÍNGUA PORTUGUESA*
}

\section{Carmi Ferraz Santos}

RESUMO: Analisaremos neste trabalho algumas modalidades do processo de formação em serviço na área de Língua Portuguesa oferecidas aos professores das séries iniciais de uma rede estadual de ensino, a fim de apreender como ocorre a "transposição didática" do saber requerido quanto ao ensino de língua escrita e estabelecer em que medida estes momentos de formação auxiliam o professor em sua tarefa de transpor este saber na sala de aula.

PALAVRAS-CHAVE: Ensino; Escrita; Formação de professores

\begin{abstract}
In this paper we shall analyze some kinds of Portuguese language inservice training offered to initial classes teacher's from a public state school network in order to elucidate how occurs the didactics transposition of required knowledge in relation to the written language teaching. Our aim is also to establish the influence this formation moments have in helping the teacher to accomplish their task of transferring that knowledge to his/her students in the classroom.
\end{abstract}

KEYWORDS: Teaching; Written; Teacher in service training

\footnotetext{
* Este texto constitui-se de parte das discussões efetuadas na dissertação Ensino de Língua Portuguesa e a formação em serviço do professor das séries iniciais apresentada ao mestrado em Educação da UFPE.
} 


\section{INTRODUÇÃO}

A sociedade tem passado por grandes avanços tecnológicos e científicos e é mister que, para se alcançar espaço na sociedade atual, se domine e critique os códigos da modernidade.

Mas, como permitir às camadas menos favorecidas o domínio de conhecimentos sistematizados, se a Escola sequer tem conseguido garantir a estas o acesso à cultura da língua escrita? Por isso, faz-se necessário que a Escola Pública proporcione a seus alunos o efetivo acesso ao conhecimento. Se os alunos têm fracassado, isto reflete a dificuldade que a escola tem tido para implantar um ensino de qualidade. Na verdade, ela tem apresentado dificuldades de ensinar os conteúdos por ela mesma propostos.

Envolvido diretamente no problema do ensino-aprendizagem está o professor. Se concebermos que o papel principal do professor é o de mediador entre o aprendiz e o conhecimento, avaliamos que se sua prática não consegue efetuar essa mediação, o trabalho escolar tornase ineficaz. Para o exercício dessa mediação, o professor precisa de um conhecimento consistente do objeto do conhecimento a ser trabalhado. Com base nesta premissa, tem-se defendido, nos últimos anos, $\mathrm{g}$ processo de formação em serviço como um dos

\footnotetext{
1 Têm sido utilizados, ao longo do tempo, diferentes terminologias para designar a formação oferecida aos profissionais da educação em exercício. O uso destas diferentes designações para o mesmo fenômeno tem sido marcada por controvérsias e divergências. Utilizaremos, neste trabalho, o termo "formação em serviço" para toda modalidade de formação oferecida ao professor, já no exercício de suas
}

momentos em que se forja a competência do professor. Este tem sido o ponto de partida de algumas propostas educacionais no sentido de permitir uma ação mais efetiva da escola.

Em especial, a problemática da leitura e da escrita tem sido objeto desses momentos de formação em serviço. No entanto, algumas pesquisas (Brasil, 1996, Leão, 1996) parecem não estabelecer uma relação direta entre tal formação e as mudanças na prática do professor.

Este trabalho se propôs investigar em que medida a formação em serviço tem contribuído para o docente das séries iniciais transpor para sua prática as novas perspectivas de ensino de Língua Portuguesa.

\section{TENDÊNCIAS DA FORMAÇÃO EM SERVIÇO}

Embora a partir dos anos de 1980, tenhase observado uma intensificação quanto aos programas de formação em serviço, desde a década anterior desenvolviam-se programas desse tipo. Estes programas têm apresentado diferentes formas, nuances e intenções de acordo com o momento político vivido pela sociedade brasileira e com a concepção de educação em voga.

No fim da década de 1960 e início dos anos de 1970, a educação brasileira foi profundamente marcada por uma visão economicista e tecnicista da fenômeno educativo. Implantaram-se neste período como estratégia de formação do

atividades, e não apenas para aquelas realizadas no âmbito escolar. 
professor os chamados "treinamentos". Aqui a didática utilizada consistia no fornecimento de uma série de métodos, recursos, procedimentos e passos a serem rigidamente seguidos no processo de ensino. A apresentação dos métodos para os professores era dissociada de uma teorização que explicasse o fenômeno pedagógico, ou seja, não havia preocupação com a lógica do sujeito a que se dirigia o processo ensinoaprendizagem nem do objeto que se queria ensinar nem com a natureza dos fatos e processos pedagógicos.

No final dos anos de 1970 e início da década de 1980, retomou-se no Brasil a discussão acerca da relação entre educação e sociedade. Vemos então despontar teorias que se propõem a explicar a educação a partir de seus condicionantes sociais. Neste período os momentos de formação em serviço foram utilizados para conscientizar o professor de seu papel transformador e instrumentalizá-lo para agir junto à classe trabalhadora, despertando-o para a necessidade de levar em conta a realidade do aluno oriundo desta classe. Buscaram-se, então, alternativas de formação em serviço que oferecessem ao professor elementos para construção de sua competência numa nova perspectiva do processo educativo.

A partir de meados da década de 1980, inicia-se um movimento de formação em serviço que tinha a preocupação de fazer chegar aos professores os resultados obtidos em diversas pesquisas produzidas no âmbito acadêmico e apresentar conhecimentos que julgava-se serem necessários para o professor dar conta de seu trabalho em sala de aula. Os novos programas de formação em serviço numa perspectiva de educação permanente propuseram-se a suprir determinadas lacunas deixadas pela formação inicial do professor. A formação em serviço passou a ser entendida como um processo contínuo e sistemático e como um dos elementos de valorização e profissionalização do docente. Das modalidades de formação em serviço oferecidas neste período foram muito frequientes os chamados "cursos". Os cursos se propunham a dar acesso a um referencial teórico adotando, muitas vezes, a crença de que a prática se deduziria da teoria. No entanto, já se pôde perceber que o simples fato de ter acesso a um conhecimento teórico não garantiu a mudança na prática, pois a prática não se deduz totalmente da teoria. Os "cursos" foram operacionalizados via "efeito multiplicador" ou "efeito de repasse", onde uma instância central concebia, planejava, elaborava materiais para os cursos; as propostas eram repassadas a uma equipe intermediária que articulava a formação em serviço e repassava os conhecimentos para os especialistas em educação que por sua vez repassavam aos professores os conteúdos destes cursos. Kramer (1995) alerta para os problemas surgidos com o "efeito multiplicador", identificados por ela como sendo as distorções, simplificações e fragmentações dos conhecimentos por parte daqueles que promovem a multiplicação ou repasse de informações.

Partindo do pressuposto que formação não se dá por acumulação, mas sim através de um processo de reflexão sobre as práticas e de (re)construção de uma identidade pessoal (cf. Nóvoa, 1995 e Schön, 1992), os estudos mais recentes acerca da formação de professores, têm- 
se valido do conceito de reflexão. A perspectiva crítico-reflexiva tem sido a tendência apontada por diversos autores (Schön,1992;

Nóvoa,1995;

Castedo,1993; Gómez, 1995) para a formação em serviço do professor. Segundo esta perspectiva a formação do professor deve estar voltada para, pelo menos, dois aspectos: o desenvolvimento profissional (produzir a profissão docente) e o desenvolvimento pessoal (produzir a "vida do professor"). Amparado no conceito de "reflexão-na-ação", os estudiosos da formação do professor defendem a tese de que esta formação deve fornecer meios para a criação de um pensamento autônomo dos docentes. Para isso, faz-se necessário investir na pessoa do professor e dar um estatuto ao saber-experiência.

Um modelo de formação em serviço que assuma o caráter de um continuum e esteja baseado numa postura críticoreflexiva, tenderá a ter como eixo fundamental a prática. Não a análise da prática como muitas propostas acabam apresentando: um desmonte do que há, sem nada colocar no lugar. Mas a prática enquanto elemento concreto, através da análise de situações didáticas experienciadas pelos professores e também sugeridas como modelos de reflexão e análise.

\section{MUDANÇAS NO SABER A SER ENSINADO NA ÁREA DE LÍNGUA PORTUGUESA}

A problemática do ensino da língua escrita tem sido uma questão muito discutida por aqueles que fazem Educação. Várias têm sido as explicações para o fracasso de muitos no processo de aprendizagem da leitura e da escrita. Atrelada a estas explicações está atrelada um modo de se entender a língua e o seu processo de ensino aprendizagem.

$\mathrm{Na}$ escola, o ensino da escrita e da leitura esteve durante muito tempo associado apenas às atividades de codificação e decodificação do sistema de escrita.

Nos últimos 30 anos, surgiu uma ampla literatura na qual se discutiu o modo como vinha se processando o ensino de língua materna no Brasil. Havia nestes trabalhos a preocupação de não apenas criticar as práticas de ensino de língua portuguesa presentes na escola, mas sobretudo apontar questões de nível conceitual e metodológico na direção de uma nova forma de se conceber o ensino da leitura e da escrita.

Já na década de 1980 alguns trabalhos das áreas da Linguiística e da Psicolinguiística passaram a questionar a noção de ensino-aprendizagem de língua escrita que concebia a língua apenas como código e, dessa forma, entendia a leitura apenas como decodificação e a escrita somente como produção grafomotriz. A linguagem deixava de ser encarada, pelo menos teoricamente, como mero conteúdo escolar e passa a ser entendida como processo de interlocução. Nesta perspectiva a língua é entendida enquanto produto da atividade constitutiva da linguagem, ou seja ela se constitui na própria interação entre os indivíduos. Passou-se, assim, a prescrever que a aprendizagem da leitura e da escrita deveria ocorrer em condições concretas de produção textual. Deslocase o eixo do ensino voltado para a 
memorização de regras da gramática de prestígio e nomenclaturas

Em propostas curriculares de diversos Estados, já a partir da década de 80, deslocou-se o eixo do ensino voltado para a memorização de regras e nomenclaturas da gramática de prestígio, para um ensino cuja finalidade é o desenvolvimento da competência lingüístico-textual, isto é, o desenvolvimento da capacidade de produzir e interpretar textos em contextos sócio-históricos verdadeiramente constituídos.

No Estado de Pernambuco, assim como em vários Estados, tem-se voltado para a formação em serviço do professor como uma das estratégias no sentido fazer chegar à escola esta nova perspectiva para o ensino da Língua Portuguesa.

\section{FORMAÇÃO EM SERVIÇO: QUESTÕES DE "TRANSPOSIÇÃO DIDÁTICA” E “CONTRATO DIDÁTICO”}

Embora tenha-se investido no Brasil, nos últimos 30 anos, em programas de formação em serviço para o professor, algumas pesquisas têm mostrado que não aprecem evidências que permitam associar estes programas de formação a melhores resultados por parte dos alunos.

Estes dados nos fizeram levantar algumas questões: como tem se estruturado a formação em serviço que se propõe trabalhar o ensino de língua em novas bases? Que limites e possibilidades são colocados pelos momentos de formação para a apropriação por parte do professor do instrumental teórico-didático neles discutido? Em que medida os momentos de formação em serviço se constituem em momentos de reflexão sobre a prática do professor?

Buscando responder a estas questões, nos propusemos a estudar algumas modalidades do processo de formação em serviço oferecidos aos professores das séries iniciais da rede pública estadual de ensino de Pernambuco. Objetivávamos analisar como aquela nova perspectiva do ensino de língua portuguesa, exposta anteriormente, tem "chegado" ao docente através da formação em serviço.

Entendendo ser o processo de formação em serviço um espaço de aprendizagem e tomando a relação formador-professor como uma relação didática, utilizamos neste trabalho dois conceitos básicos: "transposição didática" e "contrato didático". Não os utilizamos como modelos através dos quais tentaríamos encaixar a realidade, mas como lentes através das quais poderia perceber melhor como esta se constituía.

O saber científico, até chegar a ser ensinado, sofre uma série de transformações e adaptações. Yves Chevallard (1985) chamou o conjunto dessas adaptações de "transposição didática". Da escolha do saber a ensinar e sua adaptação ao sistema, existe um processo que leva a deformar, estabelecer coerência e até criar novos conhecimentos. Do resultado desse processo estabelece-se o saber escolar. No entanto, não é a totalidade do saber científico que será ensinado na escola. $\mathrm{O}$ sistema social escolar encarrega-se de designar, dentre os conhecimentos 
historicamente acumulados, aqueles pertinentes para o ensino e diversos fatores interferem na escolha destes saberes. Delimitados os "saberes a ensinar", estes são traduzidos em um conjunto de conhecimentos que caberá aos alunos aprenderem. São, então, organizados e estruturados numa progressão e constituem-se em propostas curriculares. A maneira como se dará a adaptação do conhecimento determinará o conteúdo e a forma como o saber será apreendido (Henry, 1991).

O "contrato didático" é entendido como uma "estrutura didática que põe em relação o professor e o aluno com um objeto de saber" (Johsua, 1988: 35). E, portanto, visa fundamentalmente à aquisição de saber. O "contrato didático" depende em primeiro lugar da estratégia de ensino adotada. As escolhas pedagógicas, o tipo de atividades que é solicitado ao aluno, os objetivos que orientam o ensino, são determinantes essenciais deste contrato (Henry, 1991). Faz parte, também, do "contrato didático" o gerenciamento do tempo didático na sala de aula - o que se faz, em quanto tempo - (Almouloud, 1996).

Os conceitos de "transposição didática" e "contrato didático" nos parecem ser importantes referenciais para analisar-se como são reelaboradas com os professores os conhecimentos relativos ao ensino de língua escrita e de que modo a relação didática formadorprofessor interfere na compreensão que o professor terá do objeto de conhecimento.

O objetivo de nosso trabalho foi, portanto, analisar algumas modalidades do processo de formação em serviço, oferecido aos professores das séries iniciais na Rede Estadual de Ensino de Pernambuco, a fim de apreender como ocorre a transposicão didática desse novo saber requerido quanto ao ensino de língua portuguesa e verificar como se estabelece o contrato didático entre professores e formador. Buscávamos perceber como era apresentado e discutido o conhecimento acerca da língua e sobre os processos de ensinoaprendizagem a ela relacionados.

\section{ASPECTOS METODOLÓGICOS DO TRABALHO.}

Constituíram-se objeto de nossa pesquisa três momentos de formação em serviço oferecidos aos professores da rede estadual de ensino de Pernambuco. Um destes momentos denominado de "Capacitação de Rede" teve por tema o ensino de ortografia. Durante a capacitação foi exibido o um vídeo cujo título era "Compreendendo a ortografia: o uso dos dígrafos 'rr', 'qu' e 'gu' por crianças e suas implicações pedagógicas" e procedeu-se à "discussão" do tema, a partir das questões colocadas pelo vídeo. Participaram desta capacitação cerca de cinqüenta professores duas educadoras de apoio 2 e duas diretoras.

Outros dois momentos observados foram constituídos de duas oficina pedagógicas. A primeira oficina envolveu 27 professoras e 07 educadoras de apoio e teve por título "Alternativas de construção da leitura e da escrita". A segunda oficina cujo título era "Trabalhando o livro

\footnotetext{
${ }^{2}$ Educador de Apoio é a denominação dada aos especialistas em educação da rede pública estadual de educação em Pernambuco
} 
paradidático", teve a participação de 10 professoras e 06 educadoras de apoio.

Sem desconsiderarmos os aspectos macro-estruturais que interferem no processo de formação em serviço, tínhamos a preocupação de estudá-los enquanto unidades significativas, focalizando-os em situações específicas, buscando compreender muito mais sua dinâmica de seu processo que seu produto. Em razão disto, adotamos um trabalho de abordagem qualitativa onde nos valemos basicamente de três instrumentos de coletas de dados: a observação participante com registro em fita $\mathrm{K} 7$ e registro escrito, entrevistas semi-estruturadas e análise documental.

O conteúdo da observação foi constituído da descrição da ação dos sujeitos e das atividades realizadas, assim como registro da fala dos participantes. A entrevista teve por objetivo coletar informações acerca da preparação, divulgação e escolha das temáticas e dos formadores. Com a análise documental se propôs a levantar informações sobre a política de formação em serviço para o professor, bem como sobre a perspectiva de ensino de língua apontada pela proposta de ensino da Rede.

Os dados obtidos, através dos instrumentos acima descritos, foram analisados a partir das seguintes categorias: tratamento conceitual do tema, estabelecimento do "contrato didático", relação com o cotidiano da sala de aula, estrutura de coerência da formação em serviço, estrutura de participação e conclusões dos trabalhos.

\section{ALGUNS RESULTADOS}

A análise dos momentos de formação descritos acima parece indicar que estes momentos não favoreceram o efetivo desenvolvimento profissional dos professores na medida em que não propiciaram a articulação teoria-prática, e não tinham por base um modelo reflexivo de formação. $\mathrm{E}$ ainda, reforçavam concepções e práticas tradicionais da escola questionadas nos últimos anos.

Destacaremos a seguir os resultados de nosso trabalho os quais nos permite fazer tais afirmações.

No que diz respeito à estrutura dos momentos de formação analisados, constatamos que a "Capacitação de Rede" oferecida aos professores aproximava-se de um modelo de formação tipo "curso", através do qual se procura atualizar o professor dando-lhe acesso ao que há de mais recente nas pesquisas e temas relativos ao ensino. Enquanto que as "oficinas pedagógicas" aproximavam-se de um modelo tradicional de formação do tipo "treinamento". No primeiro caso, a tônica estava na intenção de se dar acesso a um referencial teórico a partir da apresentação dos resultados de uma pesquisa, na crença de que a partir da teoria se deduziria uma nova prática. No caso das "Oficinas", o foco da preocupação das capacitadoras estava sobre o "que fazer" e "como fazer", sempre numa perspectiva puramente instrumental. Os aspectos relacionados ao "para quê" e "por quê" foram quase que completamente desconsiderados. Vemos, portanto, persistir a dicotomia teoria-prática no tratamento das questões 
do ensino tanto na "capacitação de rede", quanto na "oficina pedagógica". $\mathrm{Na}$ primeira foram "discutidos" aspectos conceituais quanto à ortografia, sem o cuidado de se refletir sobre direcionamentos didáticos, tomando a prática do professor a partir da temática. Nas oficinas, por sua vez, apresentavamse uma série de atividades a serem aplicadas em sala de aula sem que se fizesse uma análise destas atividades a partir de elementos conceituais e sem haver, tampouco, uma preocupação em se estabelecer uma reflexão sobre a prática a partir das atividades examinadas. Embora nas oficinas tenha sido bastante comum o relato de experiências, estes não constituíram-se em elementos de reflexão sobre a prática.

$\mathrm{Na}$ verdade, a apresentação das atividades nos momentos de formação ignorou as condições reais em que estas seriam aplicadas assim como não se considerou as dificuldades concretas das professoras como ponto de partida, mesmo quando faziam referência às suas práticas. Pelo contrário, do mesmo modo que parecia se ter em mente um aluno mais próximo do ideal que do real, parecia-se ter em mente também uma visão idealizada do professor.

O "contrato didático" estabelecido entre professoras e capacitadoras não diferiu em muito do contrato que se tem estabelecido tradicionalmente na escola, o que resultou numa falta de coerência entre o modelo de formação e o modelo de ensino-aprendizagem que, segundo as propostas curriculares, se quer ver nas salas de aula, os professores não experenciaram durante a formação em serviço o que se lhes sugerem como necessário e bom para seus alunos.

Coube ao professor um papel passivo de receptor de informações e executor de atividades. A participação das professoras se deu basicamente na realização de atividades e na confecção de materiais a serem supostamente utilizados em suas salas de aula. O discurso esteve quase que monopolizado pelas capacitadoras. Em todos os eventos analisados, o tempo de fala da capacitadora foi bem superior ao das participantes. E, ainda, a forma como aquelas reagiam à fala destas não estimulava a uma verdadeira participação por parte de todos. As capacitadoras escutavam as participantes quando estas intervinham, mas quase sempre não consideravam o que era por elas falado e, na maioria das vezes, continuavam a falar do "ponto onde pararam" quando ocorreram as intervenções das professoras.

Ao desprezarem os relatos das participantes sobre suas práticas, as capacitadoras desprezaram também um importante momento em que se poderiam ter utilizado estes relatos para que se refletisse acerca das práticas de ensino de língua destas professoras.

Os momentos de formação, por nós estudados, desconsideraram que o professor tem conhecimentos acerca do objeto de saber a ser ensinado e de questões didáticas que foram construídas ao longo de sua vida escolar e profissional dos quais lança mão para resolver as questões que surgem em sua prática cotidiana(Garcia, 1995). Segundo Schön (1992), é importante que os professores possam "refletir sobre seus 
próprios processos de indagação" e a reflexão sobre a prática do professor deveria ser introduzida a partir do "estudo dos contextos de trabalho" destes profissionais. A reflexão dar-se-ia, portanto, a partir "de" e "em" situações concretas. A prática do professor não seria, portanto, apenas o mote para a reflexão, seria ela própria espaço de reflexão, na medida em que não se constituiria espaço de simples aplicação de sequiências de atividades. A reflexão sobre a prática do professor traria à tona os conhecimentos que este tem acerca do objeto de saber ou prática social que se quer ensinar, acerca de questões didáticas que estão por trás do ensino daquele objeto, assim como seria espaço de reflexão da própria relação que o professor estabelece com o objeto de conhecimento ou prática social.

Com relação ao funcionamento interno dos encontros de formação, não observou-se o estabelecimento de elos coesivos entre os diferentes momentos e atividades vivenciados. Assim como na escola tradicional (Freitas, 1989), parecia que o importante era realizar as tarefas, ocupar o tempo em sala de aula, sem que se refletisse sobre os porquês e para quê das atividades propostas.

No que diz respeito ao ensino de língua escrita, nós vimos persistir, nos eventos observados, uma série de problemas já identificados na educação escolar.

Embora tenhamos observado uma certa coerência entre os princípios para o ensino de língua escrita colocados pela proposta de ensino da Rede e pelos textos de apoio que supostamente embasavam os momentos de formação, não se observou a mesma coerência entre estes textos e o que se dizia a respeito do objeto de ensino ao se discutir as atividades apresentadas. As atividades sugeridas aos professores acabaram reforçando concepções que de uma certa forma já se cristalizaram na escola e que vêm sendo amplamente discutidas. É o caso, por exemplo, da concepção do ensino de língua. $O$ ensino de língua tratado nos momentos de "capacitação", por nós observados, dizia respeito, basicamente, ao trabalho com a gramática normativa e ao ensino da ortografia pautado pela memorização. $\mathrm{O}$ trabalho com leitura e escrita apareceu sempre como momentos separados, não correspondendo ao que ocorre nas práticas sociais extra-escolares. A leitura (quando aparecia) nos momentos de formação tinha no texto apenas um pretexto para o ensino de gramática ou outro qualquer conteúdo de distintas disciplinas, verificando-se, assim, uma postura didatizante de todo e qualquer texto que possa chegar à escola. Quanto à produção escrita, muito escassa, assumiu também um sentido meramente escolar. As atividades de produção textual escrita, sugeridas nos momentos de formação analisados, envolviam sempre um texto sem referencialidade e funcionalidade histórico-social. Sugeriuse, por exemplo, escrever sobre "a vida na fazenda", porque leu-se um texto que falava do campo. Em outro momento, ao ler-se um texto sobre o nascimento de um animal, sugeriu-se a produção de um texto "sobre os animais". A única função do texto pareceu ser sempre a de uma tarefa escolar.

\section{CONCLUSÃO}

Os dados de nossa pesquisa indicam que os momentos de formação em serviço 
por nós analisados (tanto do ponto de vista da concepção de ensino de língua escrita que subjaz às atividades propostas, como na forma de participação e estruturação dos momentos da formação em serviço) não deram conta nem da discussão acerca das mudanças no saber a ser ensinado, nem da forma de transpô-lo. E, ainda, que estes momentos de formação não se constituíram em espaço de reflexão da prática do professor.

Todas estas evidências nos fazem concluir que as pesquisas que tratam da formação em serviço não podem discutir esta formação e seus efeitos apenas com base na ocorrência ou não de oportunidades oferecidas ao professor. Julgamos obrigatório examinar, cada vez mais, em que medida os modelos de formação em serviço têm contribuído efetivamente para a mudança nas formas de transpor o conhecimento na sala de aula. A pesquisa aponta para a necessidade dos momentos de formação em serviço voltarem-se para a prática do professor num movimento de reflexãoda-ação, assim como a necessidade de rever-se a própria formação do formador para que esta também insira-se num movimento de efetivo desenvolvimento profissional dos educadores.

\section{BIBLIOGRAFIA}

ALMOULOUD, S.A. Didática da matemática. São Paulo: PUC, 1996.

CASTEDO, M. L. Uma alternativa de capacitação docente para a alfabetização inicial. Bogotá, 1993 (Mimeogr.).
CHEVALLARD, Y. La transposition didactique. du savoir savant au savoir enseigné. Grnoble: Editions La Pensée Sauvage, 1985

FREITAS, L.B. de L. A produção de ignorância na escola: uma análise crítica do ensino de língua escrita na sala de aula. São Paulo: Cortez. 1989.

GARCIA, A. P. A Formação de professores: novas perspectivas baseadas na investigação sobre o pensamento do professor. In: NÓVOA, A. (Org.). Os professores e sua formação. Lisboa: Dom Quixote, p.51-76,1995.

GÓMEZ, C. M. O pensamento prático do professor: a formação do professor como profissional reflexivo. In: NÓVOA, A. (Org.). Os professores e sua formação. Lisboa: Dom Quixote, 1995. p.93-114.

HENRY, M. Didactique des mathématiques. Besançon, 1991. (Mimeogr.)

JOHSUA, S. Le "contrat didactique" et l'analyse des phénomène didactiques. Interactions Didactiques. Marseille, $\mathrm{n}$. 8, 1988.(Mimeogr.).

KRAMER, S. Alfabetização-leitura e escrita. Formação de professores em curso. Rio de Janeiro: Papéis e Cópias de Botafogo : Escola de Professores, 1995.

LEÃO, S.M. Qualidade da educação: as representações sociais dos professores. Recife, 1996. Dissertação (Mestrado em Educação). Universidade Federal de Pernambuco. 
LIBÂNEO, J.C. Democratização da escola pública: a pedagogia crítico social dos conteúdos. São Paulo: Loyola, 1985.

NÓVOA, A. (Org.). Os professores e sua formação. Lisboa: Dom Quixote, 1995.

SCHÖN, D.A. La formación de profissionales reflexivos: hacia un nuevo diseño de la enseñanza y el aprendizaje en las profissiones. Barcelona: Paidós, 1992 